depending on index of assessment. The achieved values maintained throughout the entire analyzed period (Table 2). At Wk 24, mean changes in ASDAS-CRP and BASDAI were -1.57 and -2.83 in NTK arm vs -0.11 and -0.19 in PBO arm respectively $(p<0.0001)$.

Table 1. Baseline demographics and mean composite endpoint scores

\begin{tabular}{lcc}
\hline Arm & NTK $(\mathrm{N}=54)$ & PBO $(\mathrm{N}=50)$ \\
\hline Age (years) ${ }^{*}$ & $43.5(12.16)$ & $42.7(10.76)$ \\
Male, $\mathrm{n}(\%)$ & $27(50)$ & $26(52)$ \\
PsA duration, mo & $70.0(78.78)$ & $79.0(81.62)$ \\
BASDAI score & $5.58(1.80)$ & $5.79(1.94)$ \\
ASDAS-CRP score $^{*}$ & $3.38(1.16)$ & $3.38(1.28)$ \\
nocturnal pain & $4.2(2.42)$ & $5.1(2.29)$ \\
spinal pain & $4.4(2.41)$ & $5.3(2.40)$
\end{tabular}

* mean (standard deviation) BASDAI=Bath Ankylosing Spondylitis Disease Activity Index, ASDAS-CRP=Ankylosing Spondylitis Disease Activity Score with C-reactive protein

Table 2. Changes in BASDAI and ASDAS-CRP vs baseline

\begin{tabular}{lllll}
\hline & \multicolumn{3}{c}{ BASDAI } & \multicolumn{3}{c}{ ASDAS-CRP } \\
\cline { 2 - 5 } & NTK $(\mathrm{N}=54)$ & PBO $(\mathrm{N}=50)$ & NTK $(\mathrm{N}=54)$ & PBO (N=50) \\
\hline Wk 4 & $-2.45(1.94)$ & $-0.51(1.26)$ & $-1.44(1.06)$ & $-0.19(0.60)$ \\
Wk 8 & $-2.77(2.22)$ & $-0.38(1.55)$ & $-1.53(1.07)$ & $-0.21(0.74)$ \\
Wk 16 & $-2.77(1.83)$ & $-0.17(1.67)$ & $-1.52(0.98)$ & $-0.10(0.97)$ \\
Wk 24 & $-2.83(2.15)$ & $-0.19(1.70)$ & $-1.57(1.06)$ & $-0.11(0.95)$ \\
\hline
\end{tabular}

mean (standard deviation)

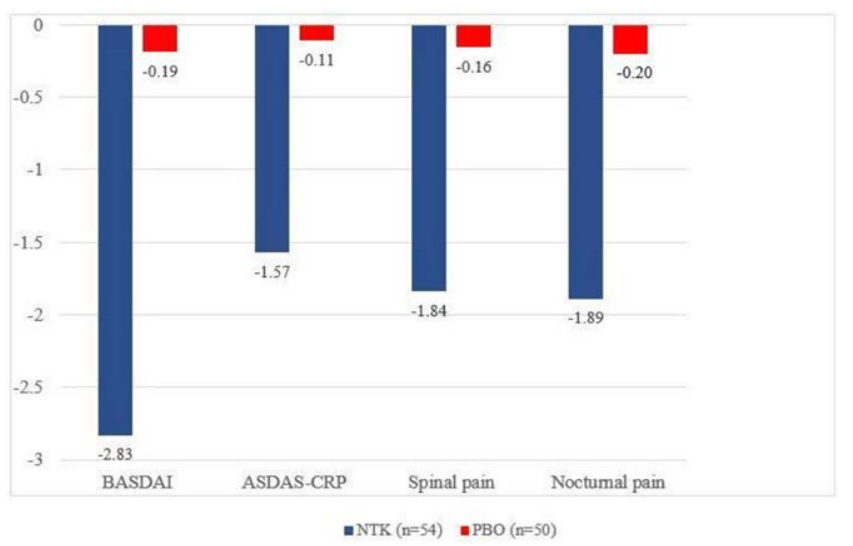

Figure 1. Mean change in BASDAI, ASDAS-CRP, spinal pain, and nocturnal pain at Wk 24

Conclusion: About $50 \%$ of subjects, randomized to PATERA study, had IBP at baseline. NTK leads to rapid and sustained improvement in axial disease in patients with active PsA.

Acknowledgments: This study was sponsored by JSC BIOCAD.

Disclosure of Interests: Tatiana Korotaeva Grant/research support from: Pfizer, Consultant of: Abbvie, BIOCAD, Bristol-Myers Squibb, Celgene, Eli Lilly, Janssen, Merck Sharp \& Dohme, Novartis, Novartis-Sandoz, Pfizer, UCB, Speakers bureau: Abbvie, BIOCAD, Bristol-Myers Squibb, Celgene, Eli Lilly, Janssen, Merck Sharp \& Dohme, Novartis, Novartis-Sandoz, Pfizer, UCB, Inna Gaydukova Grant/research support from: JSC BIOCAD, Speakers bureau: Pfizer, Novartis, AbbVie, JSC BIOCAD, Celgene, MSD, Sanofi, V Mazurov: None declared, Aleksey Samtsov Grant/research support from: JSC BIOCAD, Novartis, Eli Lilly, Johnson\&Johnson, Celgene, Glenmark, Galderma, Sanofi, Vladislav Khayrutdinov Grant/research support from: Akrikhin, Alkoy, Belupo, JSC BIOCAD, Bosnaliejk, Verteks, Glenmark, Elfa, Leo Pharma, MSD, Novartis, Pfizer, Sun Pharma, Sanofi, Celgene, Pharmtec, AbbVie, Eli Lilly, Jadran, Janssen, Andrey Bakulev Grant/research support from: AbbVie, Eli Lilly, Pfizer, UCB, MSD, Novartis, Galderma, Celgene, Leo Pharma and Johnson\&Johnson, JSC BIOCAD, Consultant of: Novartis, Celgene and Johnson\&Johnson, Speakers bureau: AbbVie, Eli Lilly, Galderma, UCB, Novartis, Celgene and Johnson\&Johnson, Muza Kokhan Grant/research support from: AbbVie, Eli Lilly, Pfizer, UCB, MSD, Novartis, Galderma, Celgene, Leo Pharma and Johnson\&Johnson, JSC BIOCAD, Consultant of: Novartis, Celgene and Johnson\&Johnson, Speakers bureau: AbbVie, Eli Lilly, Galderma, UCB, Novartis, Celgene and Johnson\&Johnson, Alena Kundzer:
None declared, Nikolaj Soroka Grant/research support from: JSC BIOCAD, Ekaterina Dokukina Employee of: JSC BIOCAD, Anna Eremeeva Employee of: JSC BIOCAD

DOI: 10.1136/annrheumdis-2020-eular.3543

\begin{tabular}{|l|l|}
\hline FRI0347 & PREVALENCE OF OBESITY AND ITS LINK TO \\
& PSORIATIC ARTHRITIS (PSA) ACTIVITY AND \\
& RESPONSE TO THERAPY: DATA FROM THE RUSSIAN \\
& PSA REGISTRY (RU-PSART)
\end{tabular}

Y. Korsakova ${ }^{1,2}$, E. Loginova3, E. Gubar3, E. Vasilenko ${ }^{4}$, A. Vasilenko ${ }^{5}$, N. Kuznetsova ${ }^{6}$, I. Patrikeeva ${ }^{7}$, T. Korotaeva ${ }^{8}$, E. Nasonov ${ }^{8}$ on behalf of RU-PsART Study Group. ${ }^{1}$ Nasonova Research Institute of Rheumatology, Department of Spondyloarthritis and Psoriatic Arthritis, Moscow, Russian Federation; ${ }^{2}$ V.A. Nasonova Research Institute of Rheumatology, Department of Spondyloarthritis and Psoriatic Arthritis, Moscow, Russian Federation; ${ }^{2}$ V.A. Nasonova Research Institute of Rheumatology, Department of Spondyloarthritis and Psoriatic Arthritis, Moscow, Russian Federation; ${ }^{4}$ Clinical Rheumatological Hospital No 25, St. Petersburg, Russian Federation; ${ }^{5}$ Novgorod Regional Clinikal Hospital, Novgorod, Russian Federation; ${ }^{6}$ Municipal Autonomous Institution "City Clinical Hospital No. 40, Ekaterinburg, Russian Federation; ${ }^{7}$ Tyumen Regional Clinical Hospital No 1, Tyumen, Russian Federation: ${ }^{8}$ V.A. Nasonova Research Institute of Rheumatology, Moscow, Russian Federation

Background: Obesity is a common comorbidity of psoriasis and PsA. It is connected to low-grade inflammation and it has a negative impact on the response to therapies. Although a high prevalence of obesity has been shown in a whole number of epidemiology and observational studies, its relationship to PsA activity has been less investigated. In the RU-PsART registry data was collected from 43 rheumatology centers of the Russian Federation

Objectives: to evaluate the prevalence of obesity and its association to PsA activity as well as its impact on therapy response in real clinical practice Methods: $614(\mathrm{M} / \mathrm{F}=331(54 \%) / 283(46 \%)$ PsA pts fulfilling the CASPAR criteria were included from the RU-PsART cohort. Mean age $45.2 \pm 0.52 \mathrm{yrs}$, PsA duration $5.7 \pm 0.27 \mathrm{yrs}$, PsO duration $15.71 \pm 0.56 \mathrm{yrs}$, DAPSA $28.79 \pm 0.75$. At baseline (BL) and $6 \mathrm{mo} / 12 \mathrm{mo}$ of observation PsA activity was evaluated by Tender Joint Count (TJC68), Swollen Joint Count (SJC66); PGA, physician global assessment by Visual Analog Scale (VAS); PtGA VAS; PtPain VAS; DAPSA and body mass index $\left(B M l, \mathrm{~kg} / \mathrm{m}^{2}\right)$ were calculated. Pts were treated with conventional/target synthetic disease-modifying antirheumatic drugs csDMARDs (55\%)/tsDMARDs (5\%), biological DMARDs (23\%), NSAID (17\%) according to physician's decision. At BL/6/12 mo all pts were categorized according to DAPSA as high activity (DAPSA $>28$ ) and

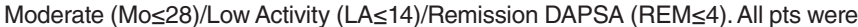
divided into three groups according to $\mathrm{BMI}\left(\mathrm{kg} / \mathrm{m}^{2}\right)$ : normal $<25$, overweight $>25-30$, obese $>30 . \mathrm{M} \pm \mathrm{m}, \%$, multivariate analysis of variance (MANOVA), ANOVA, OR $95 \%$ (Cl) were performed. All $p<0.05$, were considered to indicate statistical significance Results: The baseline BMI was $27.7 \pm 0.23 \mathrm{~kg} / \mathrm{m}^{2}$ with the following BMI categories: normal - 212 pts (34.6\%), overweight - 214 pts $(34.8 \%)$ and obese -187 $(30.45 \%)$. In all pts DAPSA significantly improved to $16.11 \pm 0.82 / 14.71 \pm 1.17$ at $6 / 12$ mo accordingly. At BL and 6/12 mo of therapy DAPSA was significantly higher in the obese pts compared to the normal and the overweight pts despite of improvements seen in all groups (table 1). By the last visit significant differences were found in DAPSA depending on BMl at BL (ANOVA, $\mathrm{p}<0.031$ ). BMl>30 at BL was associated with lower probability of DAPSA improvement from high activity to Mo/LA/REM state compared to normal BMI pts and the overweight pts: OR 2.484 (95\% Cl 1.135-5.439) and OR 2.346 (95\% Cl 1.07-5.143) accordingly (Fig 1 )

Table 1. Dynamics of DAPSA from BL to $6 / 12$ mo depending on BM categories.

\begin{tabular}{llll}
\hline BMI $\left(\mathrm{kg} / \mathrm{m}^{2}\right)$ & DAPSA BL & DAPSA 6 mo & DAPSA 12 mo \\
\hline$<25$ & $27.20 \pm 1.15$ & $13.84 \pm 1.01$ & $13.33 \pm 1.53$ \\
$25-30$ & $26.93 \pm 1.17$ & $14.48 \pm 1.43$ & $13.83 \pm 2.36$ \\
$>30$ & $32.86 \pm 1.57$ & $21.19 \pm 1.84$ & $18.92 \pm 2.54$ \\
\hline
\end{tabular}

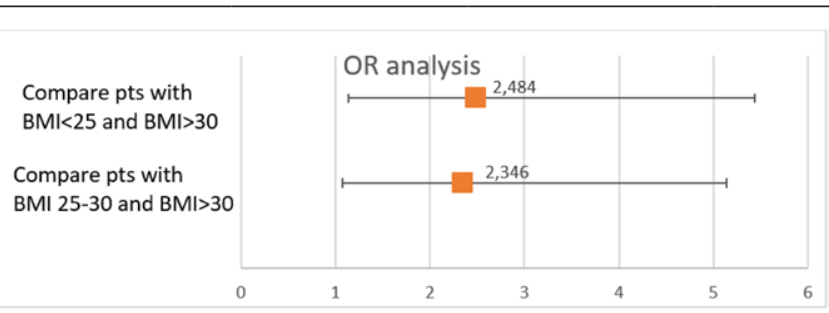

Fig. 1. OR analysis of relationship between $\mathrm{BMI}$ at $\mathrm{BL}$ and treatment response. 
Conclusion: The high prevalence of overweight/obesity PsA pts was associated with higher PsA activity and lower response to therapy in our cohort

Disclosure of Interests: Yulia Korsakova: None declared, Elena Loginova Speakers bureau: Janssen, ELENA GUBAR: None declared, Elizaveta Vasilenko: None declared, Aleksey Vasilenko: None declared, Natalia Kuznetsova: None declared, Irina Patrikeeva: None declared, Tatiana Korotaeva Grant/research support from: Pfizer, Consultant of: Abbvie, BIOCAD, Bristol-Myers Squibb, Celgene, Eli Lilly, Janssen, Merck Sharp \& Dohme, Novartis, Novartis-Sandoz, Pfizer, UCB, Speakers bureau: Abbvie, BIOCAD, Bristol-Myers Squibb, Celgene, Eli Lilly, Janssen, Merck Sharp \& Dohme, Novartis, Novartis-Sandoz, Pfizer, UCB, Evgeny Nasonov: None declared

DOI: 10.1136/annrheumdis-2020-eular.3314

\section{FRI0348 \\ PERSISTENCE OF SECUKINUMAB AND USTEKINUMAB IN PSORIATIC ARTHRITIS: A REAL- WORLD MULTICENTRIC COHORT OF 409 PATIENTS}

J. G. Letarouilly ${ }^{1}$, B. Flachaire ${ }^{2}$, C. Labadie ${ }^{3}$, N. Cohen ${ }^{2}$, M. Kyheng ${ }^{1}$, J. Sellam ${ }^{4}$, P. Richette ${ }^{5}$, P. Dieudé ${ }^{6}$, P. Claudepierre ${ }^{7}$, B. Fautrel ${ }^{8}$, E. Houvenagel ${ }^{9}$, C. D. Nguyen ${ }^{10}$, M. H. Guyot ${ }^{11}$, N. Segaud ${ }^{12}$, F. Maury ${ }^{13}$, L. Marguerie ${ }^{14}$, X. Deprez ${ }^{15}$, J. H. Salmon ${ }^{16}$, G. Baudens ${ }^{17}$, C. Miceli Richard ${ }^{18}$, E. Gervais ${ }^{19}$, I. Chary Valckenaere ${ }^{20}$, P. Lafforgue ${ }^{2}$, D. Loeuille ${ }^{20}$, C. Richez ${ }^{3}$, T. Pham ${ }^{2}$, R. M. Flipo ${ }^{21} .{ }^{1} \mathrm{CHU}$ Lille, Lille, France; ${ }^{2}$ Aix Marseille Univ, APHM, Marseille, France: ${ }^{3} \mathrm{CHU}$ Bordeaux, Bordeaux, France: ${ }^{4} \mathrm{CHU}$ Saint-Antoine, Paris, France; ${ }^{5} \mathrm{CHU}$ Lariboisière, Paris, France; ${ }^{6} \mathrm{CHU}$ Bichat, Paris, France; ${ }^{7} \mathrm{CHU}$ Henri Mondor, Paris, France; ${ }^{8} \mathrm{CHU}$ Pitié, Paris, France; ${ }^{9} \mathrm{GHICL}$, Lomme, France; ${ }^{10} \mathrm{CH}$. Béthune, Béthune, France; ${ }^{11} \mathrm{CH}$. Roubaix, Roubaix, France; ${ }^{12} \mathrm{CH}$ Armentières, Armentières, France; ${ }^{13}$ Private Practice, Beuvry, France; ${ }^{14}$ Institut Calot, Berck-sur-mer, France; ${ }^{15} \mathrm{CH}$. Valenciennes, Rhumatologie, France; ${ }^{16}$ $\mathrm{CHU}$ Reims, Reims, France; ${ }^{17}$ Private practice, Valenciennes, France; ${ }^{18} \mathrm{CHU}$ Cochin, Paris, France; ${ }^{19} \mathrm{CHU}$ Poitiers, Poitiers, France ${ }^{20} \mathrm{CHU}$ Nancy, Nancy, France; ${ }^{21} \mathrm{CHU}$ Lille, Lille, France

Background: Real-world data are missing for Ustekinumab (UST) and secukinumab (SEK) in psoriatic arthritis (PsA).

Objectives: To evaluate the characteristics of the patients (pts) with PsA treated by UST or SEK and to assess real world persistence of UST and SEK in PsA.

Methods: This is a retrospective, multicenter study of pts with PsA (CASPAR criteria or diagnosis confirmed by a rheumatologist) initiating UST or SEK with a follow-up $\geq 6$ months from January 2011 to April 2019. The comparison of persistence between UST and SEK was analysed using a Cox model with an inverse probability of treatment weighting propensity score including 11 confounding factors. Subgroup analyses (age>65 years, gender, Body Mass Index (BMI), Charlson score $>2$, psoriasis, CRP $>5 \mathrm{mg} / \mathrm{L}$, number $(\mathrm{nb})$ of prior biotherapies, proportion of pts on maximum dose of UST or SEK, combination with methotrexate (MTX), enthesitic and axial forms of PsA) were also performed to test the heterogeneity of UST and SEK persistence. Finally, 2 sensitivity analyses were performed, first excluding the pts treated before the marketing authorization of SEK, and then excluding the pts that underwent a molecule switch. Causes of discontinuation were also collected.

Results: 406 pts were included: 245 with UST and 161 with SEK. At baseline before propensity score-matching, the UST group has a higher BMI $(28.9 \pm$ $6.4 \mathrm{~kg} / \mathrm{m}^{2}$ vs. $27.4 \pm 6.0 \mathrm{~kg} / \mathrm{m}^{2}$ ), more peripheral forms ( $98 \%$ vs. $90.8 \%$ ), a higher nb of active smokers (27.1\% vs. $19.9 \%)$, a higher frequency of psoriasis $(96.3 \%$ vs. $83.2 \%$ ), less MTX users (38.9\% vs. $44.2 \%$ ), a higher nb of pts with CRP $>5 \mathrm{mg} / \mathrm{L}(54.3 \%$ vs. $47 \%)$, a higher nb of pts naïve to biotherapies (22\% vs. $13 \%)$ and a higher $\mathrm{nb}$ of pts with recommended dosing $(97.3 \%$ vs $50.9 \%)$. The median persistence was 9.4 months and 14.7 months for UST and SEK, respectively. The persistence rate was lower in the UST group compared to the SEK group $(40.9 \%$ vs. $59.1 \% \%$ at 1 year; $26.4 \%$ vs. $38.0 \%$ at 2 years; weighted $\mathrm{HR}=1.42 ; 95 \% \mathrm{Cl}$ 1.07 to 1.92; $p=0.015$ ) (Fig 1). In subgroup analysis, combination with MTX was associated with a higher persistence rate in the patients with SEK compared to those receiving UST: $43.6 \%$ vs. $23.2 \%$ ( $H R=2.20 ; 95 \% \mathrm{Cl} 1.30$ to $3.51 ; p=0.001$ ), whereas no difference was observed in SEK and UST monotherapy: $33.8 \%$ vs $28.4 \%$, respectively ( $\mathrm{HR}=1.06 ; 95 \% \mathrm{Cl} 0.74$ to $1.53 ; \mathrm{p}=0.75$ ) (Fig 2). A similar difference was found in the sensitivity analyses, with however a difference at the limit of significance for the analysis excluding pts with a molecule switch (adjusted HR=1.35; IC95\% 0.96 to $1.92 ; \mathrm{p}=0.085$ ). The causes of discontinuation were due to inefficacy in $85 \%$ of cases and an adverse event in $12 \%$ of cases (19\% in the SEK group and $9 \%$ in the UST group).

Conclusion: In this first real-world study comparing UST and SEK persistence in PsA, the persistence of SEK was longer than that of UST. Subgroup analysis revealed this difference of persistence was restricted to patients treated in combination with MTX.
Figure 1. Persistence with Ustekinumab (UST) and Secukinumab (SEK) in IPTW cohort

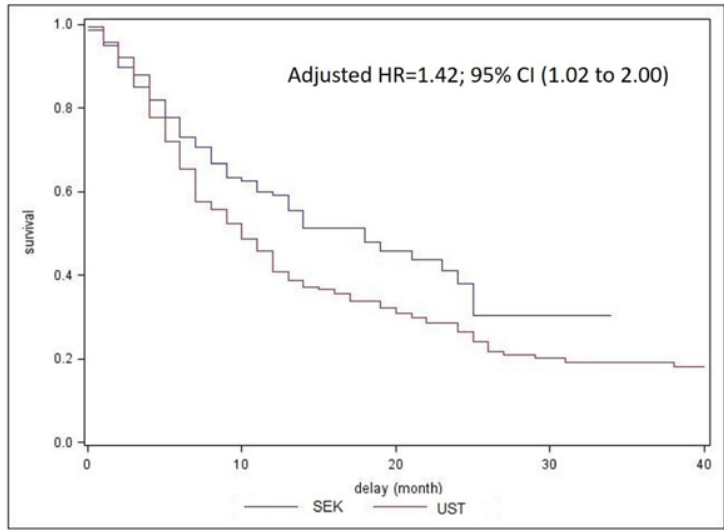

Figure 2. Follow-up 2-year persistence of molecules according to different subgroups In IPTW Cohorts

\begin{tabular}{|c|c|c|c|c|c|c|}
\hline 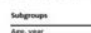 & $x_{x \rightarrow \infty}$ & $x_{n=18}$ & memoor & & $=$ & $\cdots$ \\
\hline 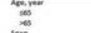 & 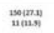 & $\operatorname{mix}_{\substack{\sin \\
\sin }}$ & 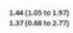 & $1:$ & onz & 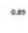 \\
\hline$=$ & 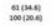 & 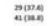 & 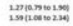 & $\because$ & $\therefore$ & $\omega$ \\
\hline 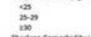 & 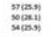 & 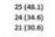 & 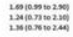 & $\because \dot{ }$ & 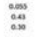 & $\cdots$ \\
\hline 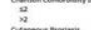 & 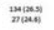 & 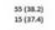 & 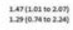 & $\therefore$ & $\because n$ & $\omega$ \\
\hline$=$ & $\lim _{\sin }$ & 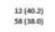 & 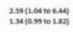 & $\cdot \cdot$ & $\because \infty$ & es \\
\hline$=$ & $\sin _{\sin }$ & $\min _{\substack{n \\
n \neq m}}$ & 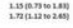 & $\because$ & $\therefore$ & ${ }^{2 x}$ \\
\hline 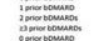 & 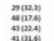 & 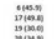 & 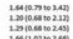 & $\because \ddot{\square}$ & 里 & on \\
\hline$=$ & 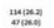 & nos & 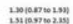 & $\because$ & $a$ & as \\
\hline$=$ & natus & 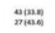 & 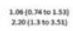 & - . & 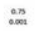 & $\cos 2$ \\
\hline$=$ & 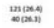 & 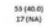 & 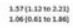 & $\cdot$ & $\stackrel{\infty}{\infty}$ & ax \\
\hline$=$ & 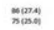 & $\underset{\substack{n \rightarrow \infty \\
n+\infty}}{n+\infty}$ & 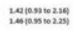 & $:$ & $\stackrel{\text { an }}{\text { and }}$ & $a n$ \\
\hline$=$ & $\operatorname{mox}_{\text {nowa }}$ & 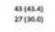 & 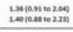 & $:$ & $\stackrel{13}{\circ}$ & $m$ \\
\hline
\end{tabular}

Disclosure of Interests: Jean-Guillaume Letarouilly Grant/research support from: Research grant from Pfizer, Benoît Flachaire: None declared, Céline Labadie: None declared, Nicolas Cohen Speakers bureau: Novartis, Janssen, Maeva Kyheng: None declared, Jérémie SELLAM: None declared, Pascal Richette: None declared, Philippe Dieudé: None declared, Pascal Claudepierre Speakers bureau: Janssen, Novartis, Lilly, Bruno Fautrel Grant/research support from: AbbVie, Lilly, MSD, Pfizer, Consultant of: AbbVie, Biogen, BMS, Boehringer Ingelheim, Celgene, Lilly, Janssen, Medac MSD France, Nordic Pharma, Novartis, Pfizer, Roche, Sanofi Aventis, SOBI and UCB, Eric Houvenagel Speakers bureau: Janssen, Novartis, Chi Duc Nguyen: None declared, Marie-Hélène Guyot: None declared, Nicolas Segaud: None declared, Frederic Maury: None declared, Laurent Marguerie: None declared, Xavier Deprez Speakers bureau: Novartis, Janssen, Jean-Hugues Salmon Speakers bureau: Novartis, Janssen, Guy Baudens: None declared, Corinne Miceli Richard: None declared, Elisabeth Gervais Speakers bureau: Novartis, Janssen, Roche, Pfizer, BMS, Abbvie, Isabelle CHARY VALCKENAERE: None declared, Pierre Lafforgue Speakers bureau: Novartis, Janssen, Damien LOEUILLE: None declared, Christophe Richez Consultant of: Abbvie, Amgen, Mylan, Pfizer, Sandoz and UCB., Thao Pham Speakers bureau: Novartis, Janssen, Lilly, Rene-Marc Flipo Speakers bureau: Novartis, Janssen, Lilly DOI: 10.1136/annrheumdis-2020-eular.746

\section{FRI0349 PSORIATIC ARTHRITIS AND CENTRAL OBESITY STRONG ASSOCIATION WITH FUNCTIONAL DISABILITY AND A WORSE QUALITY OF LIFE}

M. Lo Monaco ${ }^{1,2,3}$, G. Pistone ${ }^{1}$, G. Natoli ${ }^{1,3}$, R. Daita ${ }^{1}$, C. Argano ${ }^{1}$, L. Calvo ${ }^{1}$, R. Mallaci Bocchio ${ }^{1,3,4}$, R. Scondotto ${ }^{1,5}$, S. Corrao $0^{1,3,4} .{ }^{1}$ National Relevance and High Specialization Hospital Trust ARNAS Civico, Di Cristina, Benfratelli, Internal Medicine with Rheumatology and Dermatology, Palermo, Italy; ${ }^{2}$ School of Medicine University of Palermo, Biomedicine and Neuroscience (BIND), Palermo, Italy; ${ }^{3}$ I.E.ME.S.T., Organizational, Clinical, and Translational Research, Palermo, Italy; ${ }^{4}$ School of Medicine University of Palermo, Promozione della Salute, Materno-Infantile, Medicina Interna e Specialistica di Eccellenza "G D'Alessandro" (PROMISE), Palermo, Italy; ${ }^{5}$ School of Medicine University of Palermo, Internal Medicine, Palermo, Italy 